\title{
Sub-Acute Combined Degeneration of Spinal Cord a Rarity in Adolescence: Case Report
}

\author{
Authors \\ Parvinder Singh', Nishant Acharya ${ }^{2}$, Priyanka Sharma ${ }^{3}$ \\ ${ }^{1,2}$ Department of Paediatrics, Dr. RKGMC Hamirpur (H.P), India \\ ${ }^{3}$ Department of OBG, Bhandari Hospital Hamirpur (H.P), India \\ *Corresponding Author \\ Nishant Acharya
}

\begin{abstract}
Sub-acute combined degeneration of spinal cord is a common manifestation of Vitamin B12 deficiency in the age group of more than 40 years. But it has been rarely reported in paediatric age group. We hereby illustrating a case of 17 years male adolescent diagnosed to have this neurological manifestation of Vitamin B12 deficiency. Patient was started on parenteral Vitamin B12 followed by oral folic acid and iron supplementation and showed gradual symptomatic improvement.

Keywords: Neurological manifestations of B12 deficiency, Sub-acute combined degeneration of spinal cord, Demyelination, non compressive myelopathy.
\end{abstract}

\section{Introduction}

Sub-acute combined degeneration of spinal cord (SACD), a neurological manifestation resulting from vitamin B12 deficiency is characterized by the degenerative changes in spinal cord (posterior \& lateral column). This disease entity is more common in strict vegans as vitamin B12 is not present in any of the plant food except fortified cereals. The changes involving spinal cord are most commonly noticed in cervical and thoracic segments of the spinal cord on magnetic resonance imaging (MRI). These changes show reversibility on treatment with parentral vitamin B12.

\section{Case Report}

A 17 years male adolescent presented to outpatient department with complaint of weakness of both lower limbs for one and half month. The onset of weakness was insidious and it progressed asymmetrically and was also associated with paleness of body, easy fatigability, loss of appetite, mood changes and recent onset poor scholastic performance. Patient was strict vegetarian. There was no associated fever, weight loss and pain in the spine or limbs. Examination revealed severe pallor, bald tongue, knuckle hyperpigmentation, upper motor neuron signs of hypertonia, brisk deep tendon reflexes, absent superficial reflexes, ankle and patellar clonus, positive babinski along with sensory involvement i.e absent position and vibration sense. Gait was ataxic and high stepping, along with positive Rhomberg's sign suggestive of posterior and lateral column involvement. Patient as investigated (Table 1) which revealed pancytopenia along with dimorphic smear, macroovalocytes, low 
reticulocyte count and hypersegmented neutrophils suggestive of B12 deficiency. This was confirmed by low serum levels and MRI findings (figure 1). Patient was started on daily parenteral vitamin B12 for one week which was followed by improved appetite, reticulocytosis and an increase in haemoglobin by approximately $1 \mathrm{~g} / \mathrm{dl}$. On long term follow up on biweekly parenteral Vitmain B12 there was a dramatic improvement in gait and neurological manifestations.

Table 1: Investigation chart.

\begin{tabular}{|c|c|c|c|}
\hline S.no. & Investigations & $20 / 10$ & $30 / 10$ \\
\hline 1. & Haemoglobin & $6.3 \mathrm{~g} / \mathrm{dL}$ & $7.7 \mathrm{~g} / \mathrm{dL}$ \\
\hline 2. & Haematocrit & $20.1 \%$ & $23.1 \%$ \\
\hline 3. & $\mathrm{MCV} / \mathrm{MCH} / \mathrm{MCHC}$ & $84.7 / 26.7 / 31.5$ & $88.8 / 25.3 / 28.5$ \\
\hline 4. & PLATELETS & $140000 / \mu \mathrm{L}$ & $283000 / \mu \mathrm{L}$ \\
\hline 5. & TLC & $1360 / \mu \mathrm{L}$ & $8200 / \mu \mathrm{L}$ \\
\hline 6. & DLC & $\mathrm{N}_{30} \mathrm{~L}_{65} \mathrm{M}_{3} \mathrm{E}_{2} \mathrm{~B}_{0}$ & $\begin{array}{llll}\mathrm{N}_{84} & \mathrm{~L}_{12} & \mathrm{M}_{2} & \mathrm{E}_{2} \\
\mathrm{~B}_{0} & & \end{array}$ \\
\hline 7. & BUN/Creatinine & $14 / 0.51$ & \\
\hline 8. & $\mathrm{Na} / \mathrm{K} / \mathrm{Cl}$ & $130.7 / 4.17 / 108.2$ & \\
\hline 9. & $\mathrm{Ca} / \mathrm{P}_{4} / \mathrm{Mg} / \mathrm{ALP}$ & $8.0 / 4.3 / 1.7 / 104$ & \\
\hline 10. & $\mathrm{TSB} / \mathrm{CB}$ & $1.9 / 0.9$ & \\
\hline 11. & SGOT/SGPT/LDH & $34 / 40 / 3021$ & \\
\hline 12. & Vitamin B12 levels & $90 \mathrm{pg} / \mathrm{mL}$ & \\
\hline 13. & ANA & Negative & \\
\hline 14. & DCT & Negative & \\
\hline 15. & ICTC & NR & \\
\hline 16. & Peripheral Smear & $\begin{array}{l}\text { Severe } \\
\text { anisopoikilocytosis } \\
\text { with both } \\
\text { macrocytic and } \\
\text { microcytic } \\
\text { hypochromic cells, } \\
\text { tear drop cells, } \\
\text { macro-ovalocytes } \\
\text { and } \\
\text { polychromatophillic } \\
\text { cells with hyper- } \\
\text { segmented } \\
\text { neutrophils. }\end{array}$ & $\begin{array}{l}\text { Moderate } \\
\text { aniso- } \\
\text { poikilocytosis } \\
\text { with both } \\
\text { macrocytic } \\
\text { and } \\
\text { microcytic } \\
\text { hypochromic } \\
\text { cells, tear drop } \\
\text { cells, macro- } \\
\text { ovalocytes, } \\
\text { mild to } \\
\text { moderate } \\
\text { hypochromia. } \\
\text { Moderate } \\
\text { Dimorphic } \\
\text { Anaemia }, \\
\text { predominantly } \\
\text { Macrocytic }\end{array}$ \\
\hline 17. & Reticulocyte count & $0.26 \%$ & $0.7 \%$ \\
\hline 18. & USG-Abdomen & Normal study & \\
\hline 19. & MRI Brain & Normal study & \\
\hline 20. & MRI Dorsal spine & \multicolumn{2}{|c|}{$\begin{array}{l}\text { Abnormal T2 STAR hyper-intensities } \\
\text { in dorsal spinal cord involving } \\
\text { posterior aspect with inverted 'V' } \\
\text { appearance with no contrast } \\
\text { enhancement, possibility of Sub-acute } \\
\text { Combined degeneration of spinal } \\
\text { cord (SACD) [Figure 1 ] }\end{array}$} \\
\hline
\end{tabular}

\section{Discussion}

Vitamin B12 deficiency is characterized commonly by haematological, dermatological and rarely neurological manifestations. Later occurs mostly after the age of 40-50 years, while other manifestations have common occurrence in both paediatric as well as adult age group. Subacute combined degeneration of spinal cord is a treatable non compressive myelopathy with affection of the posterior and lateral spinothalamic tracts caused by deficiency of vitamin B12, resulting from myelin damage in posterior and lateral columns. Areas mostly involved are the lower cervical and upper dorsal spine $^{[1]}$. Decreased B12 levels impair function of Methionine synthetase and Methylmalonyl CoA mutase, which leads to production of abnormal fatty acids and elevated levels of Methylmalonic acid, toxic to myelin. Swelling of myelin sheaths is followed by astrocytic gliosis $^{[2]}$. Similar impairment of Methionine synthetase is also seen in cases where Nitrous Oxide has been used for anaesthesia, possible cause being pre-existing subclinical B12 deficiency ${ }^{[3]}$. Clinical presentation is with paraesthesia, loss of position and vibration sense and progressive spastic and ataxic weakness. Myelopathy is diffuse and signs asymmetric. Similar symptoms were present in our case. Loss of superficial reflexes due to associated peripheral neuropathy may be seen. Optic atrophy and disturbed mental function (megaloblastic madness) may also be associated. Visual 
disturbance due to optic neuritis may also be seen ${ }^{[2]}$. Vitamin B12 deficiency disease, specially associated with pernicious anaemia is a relatively rare disease in the developing countries. It is an essential vitamin for DNA and fatty acid synthesis, including myelin synthesis ${ }^{[4]}$. The differential diagnosis of an MRI with spinal posterior cord lesion is vast and can include multiple sclerosis, infectious myelitis, spinal infarction, HIV myelopathy and malignancies. Sub-acute combined degeneration demonstrates contiguous involvement in the posterior column of multiple segments of the cord. However, in other aetiologies of demyelinating lesions, the spinal lesions are scattered and often do not involve more than two vertebral bodies in length ${ }^{[5]}$. Checking serum B12 is used to confirm the diagnosis. However, when the level of vitamin B12 is in the low normal range, high serum levels of methylmalonic acid and homocysteine should be used to coin the diagnosis. Resolution of spinal lesions on MRI might precede the clinical improvement by several months ${ }^{[6]}$. However, diagnostic delay and/or late initiation of therapy may result in permanent irreversible injury to the spinal cord with little or no improvement on treatment.

\section{Conclusion}

Vitamin B12 deficiency is among the treatable causes of non-compressive myelopathy and a high index of suspicion should always be kept if the findings are associated with anaemia. Early parenteral vitamin B12 supplementation leads to dramatic response in the haematological and neurological manifestations. Patient should be kept on long term follow up after stopping the vitamin B12 supplementation to rule out pernicious anaemia which can be confirmed by anti parietal cell antibodies.

\section{References}

1. Srikanth SG, Jayakumar PN, Vasudev MK, Taly AB, Chandrashekhar HS. MRI in Subacute Combined Degeneration of Spinal
Cord: A case report and review of literature. Neurology India, 2002; 50: 310 - 312.

2. Beal MF, Martin JB. Nutritional and Metabolic diseases of the Nervous system. In Harrison's principles of Internal Medicine. 14th edition, 1998: 2456. Mc Graw Hill Book Co, Singapore.

3. M. A. Singer, C. Lazaridis, S. P.Nations, and G. I.Wolfe, "Reversible nitrous oxideinduced myeloneuropathy with pernicious anemia: case report and literature review," Muscle and Nerve, vol.37, no.1, pp.125-129, 2008.

4. Wadia RS, Bandishri S, Kharche Vit.B12 and folate deficiency; incidence and clinical features. Neurol.India. 2000; 48 (4): 302-4.

5. Ravina B, Loevner LA, Bank W: MR findings in subacute combined degeneration of the spinal cord: a case of reversible cervical myelopathy. AJR Am J Roentgenol. 2000, 174: 863-865.

6. P. Berlit, A. Ringelstein, and T. Liebig, "Spinal MRI precedes clinical improvement in subacute combined degeneration with B12 deficiency," Neurology, vol.63, no.3, article592, 2004. 